\title{
Inhibition of TGF- $\beta$ modulates macrophages and vessel maturation in parallel to a lowering of interstitial fluid pressure in experimental carcinoma
}

\author{
Alexei V Salnikov ${ }^{1}$, Pernilla Roswall ${ }^{2}$, Christian Sundberg ${ }^{1}$, Humphrey Gardner ${ }^{3}$, \\ Nils-Erik Heldin ${ }^{2}$ and Kristofer Rubin ${ }^{1}$ \\ ${ }^{1}$ Department of Medical Biochemistry and Microbiology, Uppsala University, Uppsala, Sweden; ${ }^{2}$ Department \\ of Genetics and Pathology, Rudbeck Laboratory, Uppsala, Sweden and ${ }^{3}$ Department of Research Pathology, \\ Biogen Idec Inc., Cambridge, MA, USA
}

\begin{abstract}
A pathologically elevated interstitial fluid pressure (IFP) is a characteristic of both clinical and experimental carcinoma. The soluble TGF- $\beta$ receptor type II-murine Fc:IgG ${ }_{2 A}$ chimeric protein (Fc:T $\beta R$ II) lowers IFP in the KAT-4 experimental model for anaplastic thyroid carcinoma. Analyses of messenger RNA (mRNA) expressions by Affymetrix microarrays and RNase protection assays, as well as of protein expressions identified tumor macrophages as targets for Fc:T/RII. Treatment with Fc:T $\beta$ RII reduced albumin extravasation, increased coverage of $\alpha$-smooth muscle actin-positive cells and reduced expression of NG2, a marker of activated pericytes, in KAT-4 carcinoma blood vessels. Specific inhibition of interleukin-1 (IL-1), a major cytokine produced by activated macrophages, lowered carcinoma IFP to a similar degree as Fc:T $\beta$ RII but had no significant effect on the parameters of blood vessel maturation. Neither Fc:T $\beta$ RII nor inhibition of IL1 changed blood vessel density. Finally, pretreatment of KAT-4 carcinomas with Fc:T $\beta$ RII increased the antitumor efficacy of doxorubicin. Our data emphasize a potential role of tumor macrophages in carcinoma physiology and identify these cells as potential stromal targets for treatment aimed to improve efficacy of chemotherapy.

Laboratory Investigation (2005) 85, 512-521, advance online publication, 14 February 2005; doi:10.1038/labinvest.3700252
\end{abstract}

Keywords: anaplastic thyroid carcinoma; growth factors; interleukins; vasculature; xenograft tumors; soluble receptors

Resistance of tumors to chemotherapy can in part be explained by impaired delivery of chemotherapeutic agents into the tumor tissue. ${ }^{1}$ The pathologically elevated interstitial fluid pressure (IFP), a characteristic of solid malignancies, reflects a barrier for drug transport into tumors. ${ }^{2-7}$ An increased IFP reduces the transcapillary pressure gradient driving outward fluid flux over the capillary wall. ${ }^{8}$

Rapid and transient lowering of IFP in experimental carcinoma increases convective transport of low molecular mass compounds into the carcinoma tissue, as well as efficacy of chemotherapy during the time period of lowered tumor IFP. ${ }^{5-7}$ Long-term

Correspondence: Professor K Rubin, PhD, Department of Medical Biochemistry and Microbiology, Uppsala University, BMC, Box 582, SE-751 23 Uppsala, Sweden.

E-mail: Kristofer.Rubin@imbim.uu.se

Received 10 October 2004; revised 20 December 2004; accepted 21 December 2004; published online 14 February 2005 treatment with inhibitors of the platelet-derived growth factor (PDGF), ${ }^{9}$ vascular endothelial growth factor (VEGF) ${ }^{10}$ systems or with dexamethasone ${ }^{11}$ lowers tumor IFP in several experimental carcinoma models. Lowering of tumor IFP by inhibition of PDGF parallels an increased uptake of and sensitivity to cytostatic drugs. ${ }^{12,13}$ Furthermore, lowering of tumor IFP by treatment with a specific inhibitor of VEGF paralleled the increased efficacy of conventional chemotherapy for human rectal carcinoma. ${ }^{14}$ Thus, available data suggest that enhancement of drug delivery to solid malignancies by reduction of tumor IFP constitutes an attractive modality to augment efficacy of conventional chemotherapy. The pathogenic mechanisms involved in the generation of the high tumor IFP are not fully known although several mechanisms have been suggested (for a recent review, see Heldin et $a 1^{15}$ ).

TGF- $\beta$ is believed to play a dual role during the progression of carcinoma towards a malignant 
metastatic phenotype; ${ }^{16}$ during early stages, negatively controlling carcinoma cell proliferation and at later stages promoting metastases. Long-term presence of $F_{C}: T \beta R I I$ suppresses metastasis formation in experimental tumor models. ${ }^{17,18}$ Treatment of xenograft human KAT-4 anaplastic thyroid carcinoma in mice with a soluble TGF- $\beta$ receptor type IImurine $\mathrm{Fc}_{\mathrm{C}} \mathrm{IgG}_{2 \mathrm{~A}}$ chimeric protein (Fc:T $\beta \mathrm{RII}$ ) lowered tumor IFP in a dose- and time-dependent manner. ${ }^{19}$ The present study was initiated to delineate potential mechanisms by which Fc:T $\beta$ RII reduced KAT-4 carcinoma IFP. KAT-4 carcinomas were chosen since they are well characterized and cultured KAT-4 carcinoma cells are refractory to TGF- $\beta .^{19}$

\section{Materials and methods}

\section{Reagents}

The TGF- $\beta$ receptor type II-murine $\mathrm{Fc}_{\mathrm{C}} \mathrm{IgG}_{2 \mathrm{~A}}$ chimeric protein (Fc:T $\beta$ RII) has been described previously. ${ }^{20}$ Human interleukin-1 receptor antagonist (rh-IL-1 Ra; Kineret) was from Amgen (Louisville, KY, USA). Anti-mouse CD31/PECAM-1 monoclonal antibody (Mab), biotin anti-mouse panendothelial cell antigen Mab, anti-mouse Ly-6G and Ly-6C (Gr-1) (RB6-8C5) Mab and FITC-conjugated anti-mouse IA/I-E (2G9) Mab were from BD PharMingen (San Diego, CA, USA). Rat anti-mouse F4/80 Mab was from Serotec (Oxford, UK). Goat anti-actin (I-19) IgG was from Santa Cruz Biotechnology (Santa Cruz, CA, USA). Rabbit polyclonal anti-laminin IgG and FITC-conjugated mouse anti- $\alpha$ smooth muscle actin $(\alpha \mathrm{SMA}) \mathrm{Mab}$ (clone 1A4) were from Sigma (St Louis, MO, USA), rabbit polyclonal anti-NG2 IgG was from Chemicon (Temecula, CA, USA), Alexa Flour 488 goat anti-rabbit $\operatorname{IgG}(\mathrm{H}+\mathrm{L})$ and Alexa Fluor 594 goat anti-rat $\operatorname{IgG}(\mathrm{H}+\mathrm{L})$ were from Molecular Probes (Eugene, OR, USA). Tumor cells were visualized with rabbit anti-TPA:B1 IgG (Sangtec Medical AB, Bromma, Sweden). Anti-mouse LYVE-1 IgG detecting lymphatic vessel endothelial HA-receptor-1 and anti-mouse VEGFR-3 (AFL-4) Mab were kindly supplied by Dr Kari Alitalo (University of Helsinki, Finland). Human and murine VEGF ELISA kits were from R\&D Systems (Abingdon, Oxon, UK).

\section{Tumors and Treatments}

KAT-4 anaplastic thyroid carcinoma cells ${ }^{21}$ were injected subcutaneously (s.c.) in the left flank of athymic C57 bl/6 mice as described. ${ }^{19,22}$ After 6-10 weeks, mice with size-matched KAT-4 tumors (approximately $0.5-1 \mathrm{~cm}^{3}$ ) received $\mathrm{Fc}$ :T $\beta$ RII, $\mathrm{IgG}_{2 \mathrm{~A}}$ or rh-IL-1 Ra. Fc:T $\beta$ RII or IgG $_{2 \mathrm{~A}}$ was given as a single intravenous (i.v.) dose of $10 \mathrm{mg} / \mathrm{kg}$. Tumors were excised and investigated after 10 days. rh-IL-1 Ra (7.5 mg/injection) was administered s.c. twice daily for 10 days.
Doxorubicin (Adriamycin, Pharmacia, Stockholm, Sweden) was given intraperitoneally (i.p.) at a dose of $3 \mathrm{mg} / \mathrm{kg}$ every second day during a 2 -week period, starting 10 days after administration of a single dose of Fc:T $\beta$ RII $(1 \mathrm{mg} / \mathrm{kg})$ or IgG $_{2 \mathrm{~A}}$ to KAT-4 carcinomabearing mice. Control animals received a single injection of Fc:T $\beta$ RII at a dose of $1 \mathrm{mg} / \mathrm{kg}$. The effect of treatment was assessed by evaluating the size of tumor viable tissue at the end point of the experiment. The relative size of tumor viable tissue was measured on representative tumor sections using the NIH Image 1.62 software. Evaluation of the relative size of viable tumor tissue gave more accurate data on antitumor effects of treatment than external size measurements due to morphology of KAT-4 tumors.

Tumor IFP was measured by the 'wick-in-the needle' technique as described. ${ }^{5}$ All animal experiments were approved by the Ethical Committee for Animal Experiments in Uppsala (Sweden). The number of animals was minimized to comply with guidelines from the Ethical Committee.

\section{Affymetrix Microarrays}

Total RNA was extracted from KAT-4 carcinomas using a LiCl/Urea-method. ${ }^{23}$ Preparation of labeled cRNA probe was performed according to recommendations from Affymetrix Inc. Poly(A) messenger RNA (mRNA) was isolated and used as template for double-stranded cDNA synthesis with an oligo(dT)24 primer containing a T7 RNA polymerase promoter site added to the $3^{\prime}$ end. The cDNA was extracted with phenol-chloroform, ethanol-precipitated, and used as a template for in vitro transcription with biotin-labeled nucleotides. Labeled cRNA was fragmented and a hybridization mix was generated. Aliquots of each sample $(10 \mu \mathrm{g}$ cRNA in $200 \mu$ l hybridization mix) were hybridized to a Gene-chip Mu74Av2 array. Scanned files in the 'Cel' format from arrays lacking significant artifacts were exported to the Rosetta Resolver software suite. Intensity ANOVA analysis was performed to reveal transcripts with differences in expression between treated with Fc:T $\beta$ RII or $\operatorname{IgG}_{2 \mathrm{~A}}$ groups with $P \leq 0.05$.

\section{Morphological Analyses}

Immunohistochemistry and double immunofluorescence stainings of cryosections were performed as previously described. ${ }^{24,25}$ The density of macrophages and granulocytes was determined using a counting grid (15-34 vision fields, $\times 500$ ). Results are expressed as cell density per $\mathrm{mm}^{2}$ of the tumor viable zone and as a percent of total cellular density. Analyses by confocal microscopy were made with a Leica TCS SP spectral confocal microscope (Leica Microsystems Heidelberg $\mathrm{GmbH})$. 


\section{In Vivo Perfusion and Permeability Assay}

After treatment with Fc:T $\beta$ RII, IgG $_{2 \mathrm{~A}}$ or rh-IL-1 Ra perfused tumor vessels were visualized using FITCDextran (mean molecular mass $2000 \mathrm{kDa}$; Sigma). Vascular permeability was assessed by determining Evans blue dye (EBD) leakage into the tumor interstitium. EBD (Sigma, $30 \mathrm{mg} / \mathrm{kg}$ ) was administered i.v. $30 \mathrm{~min}$ and FITC-Dextran $(100 \mathrm{mg} / \mathrm{kg})$ 2 min before killing an animal. To evaluate perfused area of tumor vasculature and leakage of EBD, either $50 \mu \mathrm{m}$ formalin-fixed tissue sections were analyzed by confocal microscopy or $20 \mu \mathrm{m}$ frozen sections by fluorescent microscopy. Vascular leakage was quantified based on the amount and distribution of extravasated EBD and was graded from 0 to +++ . Data were dichotomized into two groups: one low leakage group $(0$ and +$)$ and one high leakage $(++$ and +++$)$. Data are presented as percentage of vessels with high leakage for EBD in 12 fields of vision from six sections per tumor taken $100 \mu \mathrm{m}$ apart and assessed under low magnification. The extent of EBD leakage was analyzed by densitometry using the NIH Image 1.62 software. Digital images were analyzed in a gray-scale mode and dye density in tumor sections presented as number of pixels per area of tumor tissue.

\section{Immunoblot Analysis}

Viable parts of KAT-4 tumors were dissected out and lysed as previously described. ${ }^{19}$ The pellet (25 $000 \mathrm{~g}$ ) of insoluble cellular components from the lysis was subjected to sonication in $50 \mathrm{mM}$ Tris $\mathrm{HCl} \mathrm{pH} 7.4$, $5 \mathrm{mM}$ EDTA and 1\% sodium dodecylsulfate. Immunoblot analyses were performed as previously described, ${ }^{19}$ on both cell fractions using the antiNG2 or anti- $\alpha$ SMA antibodies. The second solubilization appeared to contain approximately 70-80\% of the specific signal in the NG2 immunoblots.

\section{RNase Protection Assay}

Total RNA was extracted from tumor tissues as described above. RNase protection assay (RPA) was performed using BD RiboQuant Multi-Probe RPA System kits (mCK-2b, mAngio-1 and hAngio-1) (BD Biosciences). The mRNA expression levels were measured using a Phosphor Imager (Fuji 2000, Fuji, Tokyo, Japan). The levels were normalized to L32 (mouse) or GAPDH (human) housekeeping genes and presented as relative mRNA expression.

\section{Determination of VEGF Protein Level in KAT-4 Tumors}

Specimens from the viable zone of KAT-4 tumors were extracted $(1: 10 \mathrm{w} / \mathrm{v})$ in $50 \mathrm{mM}$ Tris-HCl pH 7.5, $5 \mathrm{mM}$ EDTA, $1 \mathrm{M} \mathrm{NaCl,} 1 \%$ NP-40, $0.26 \% \mathrm{Na}-$ deoxycholate, $50 \mathrm{mM} \mathrm{NaF}, 50 \mathrm{mM} \beta$-glycerophos- phate and protease inhibitors, homogenized by freeze-thawing and cleared by centrifugation at $17000 \mathrm{~g}$ for $20 \mathrm{~min}$. A volume of $1 \mathrm{M} \mathrm{NaCl}$ was used to extract VEGF bound to heparan sulfate proteoglycans in the extracellular matrix (ECM) or cell surfaces. Supernatants were diluted five times with $10 \mathrm{mM}$ Tris-HCl prior to measurements. Total protein concentration in the specimens was determined using the bicinchoninic acid protein assay (BCA, Pierce, Rockford, IL, USA) and VEGF determined using a commercial ELISA kit (R\&D Systems).

\section{Statistical Methods}

The unpaired, two-tailed Student's $t$-test and the Mann-Whitney $U$-test were used. $P<0.05$ was considered statistically significant. Standard deviations of data points are indicated in the figures.

\section{Results}

\section{Fc:T $\beta$ RII Downregulates Genes Expressed by Macrophages}

Available data suggest that treatment with Fc:T $\beta$ RII modifies host rather than carcinoma cell activity in KAT-4 tumors. ${ }^{19}$ Expression of mouse (host) genes was investigated by mouse Affymetrix microarray analyses. Differences in gene expressions in carcinomas from animals treated with Fc:T $\beta$ RII $(n=3)$ or $\operatorname{IgG}_{2 \mathrm{~A}}(n=3)$ were compared. A set of 281 genes out of the totally $\sim 1.25 \times 10^{4}$ genes presented on the chips were significantly changed ( $P<0.05$; ANOVA). Of these genes, 41 were either upregulated by $\geq 100 \%$ or downregulated by $\geq 50 \%$ (Table 1 ).

Several genes known to be expressed by macrophages were significantly downregulated after treatment with Fc:T $\beta$ RII (Table 1). These genes included S100 calcium-binding protein A9, major histocompatibility complex (MHC) class II antigens, mannose receptors, IL-1 $\beta$ and monocyte chemotactic protein2 (MCP-2). Most of the highly expressed genes encoding ECM proteins were not regulated in KAT-4 carcinomas subjected to TGF- $\beta 1$ and $-\beta 3$ inhibition, for example, genes encoding interstitial collagens (data not shown). The only ECM protein that was significantly downregulated was the small leucinerich repeat proteoglycan, fibromodulin. Genes encoding the hemoglobin A- and B-chains were most markedly upregulated. The significance of the latter finding is unclear.

RPA and immunofluorescence stainings were performed to validate the microarray results. RPA of several mouse cytokine genes revealed a specific downregulation of IL-1 $\beta$ and IL-1Ra (Figure 1a). The IL-1Ra gene was not included in the microarrays. In agreement with the microarray data, quantitative morphological analyses showed that the number of macrophages was reduced by around $30 \%$ in tumors treated with Fc:T $\beta$ RII $(n=5)$ compared to control 
Table 1 Changes in gene expression in xenografted human anaplastic thyroid carcinoma after inhibition of TGF- $\beta 1$ and $-\beta 3$

\begin{tabular}{|c|c|c|c|c|}
\hline \multirow[t]{2}{*}{ Accession no. } & \multirow[t]{2}{*}{ Description } & \multirow[t]{2}{*}{ Fold change } & \multicolumn{2}{|c|}{ Intensity } \\
\hline & & & 1 & 2 \\
\hline \multicolumn{5}{|c|}{ Immune system associated genes } \\
\hline M83219 & S100 calcium-binding protein A9 & -4.16 & 0.61 & 0.15 \\
\hline U35330 & Histocompatibility 2, class II, locus Mb1 & -3.73 & 0.47 & 0.13 \\
\hline M21932 & Histocompatibility 2 , class II antigen A, beta 1 & -3.62 & 5.49 & 1.54 \\
\hline AB023418 & MCP-2/CCL8 & -3.09 & 9.15 & 3 \\
\hline L43371 & Hydrogen peroxide inducible protein 53 & -2.7 & 0.33 & 0.12 \\
\hline M15131 & Interleukin 1 beta & -2.68 & 0.33 & 0.13 \\
\hline U35330 & Histocompatibility 2, class II, locus Mb1 & -2.63 & 1.17 & 0.45 \\
\hline X12905 & Properdin factor, complement & -2.46 & 1.17 & 0.48 \\
\hline M23158 & Leukocyte common antigen, exon 33 & -2.18 & 0.27 & 0.12 \\
\hline Z11974 & Mannose receptor, C type 1 & -2.11 & 1.42 & 0.68 \\
\hline \multicolumn{5}{|c|}{ Vasculature associated genes } \\
\hline X59556 & Endothelin 2 & 2.34 & 0.12 & 0.29 \\
\hline \multicolumn{5}{|l|}{ Growth factors } \\
\hline AJ009862 & Transforming growth factor, beta 1 & -2.2 & 0.81 & 0.38 \\
\hline AF100906 & Bone morphogenetic factor 11 (Bmp11) & 2.26 & 0.13 & 0.29 \\
\hline \multicolumn{5}{|c|}{ Enzymes and metabolism } \\
\hline AI181346 & Carboxylesterase 3 & 2.21 & 0.13 & 0.28 \\
\hline AV086797 & Creatine kinase, muscle & 2.27 & 0.29 & 0.68 \\
\hline AF029843 & Phosphoglycerate mutase 2 & 2.37 & 0.13 & 0.3 \\
\hline \multicolumn{5}{|l|}{ Receptors } \\
\hline M34476 & Retinoic acid receptor, gamma & -2.41 & 0.3 & 0.13 \\
\hline AF016271 & Cadherin 16 & 2.03 & 0.12 & 0.25 \\
\hline D13517 & Asialoglycoprotein receptor 1 & 2.37 & 0.13 & 0.3 \\
\hline \multicolumn{5}{|l|}{ Others } \\
\hline M13805 & Mouse type I epidermal keratin mRNA, clone pkSCC-50, $3^{\prime}$ end & -5.27 & 0.65 & 0.13 \\
\hline U51112 & Solute carrier family 9 (sodium/hydrogen exchanger), member 1 & -4.52 & 0.55 & 0.12 \\
\hline $\mathrm{U} 15784$ & Src homology 2 domain-containing transforming protein $\mathrm{C} 1$ & -2.82 & 0.34 & 0.12 \\
\hline U68058 & Frizzled-related protein & -2.3 & 0.29 & 0.13 \\
\hline M13805 & Mouse type I epidermal keratin mRNA, clone pkSCC-50, $3^{\prime}$ end & -2.19 & 2.31 & 1.07 \\
\hline AW050325 & Crystallin, lambda 1 & -2.11 & 0.99 & 0.48 \\
\hline U70132 & Paired-like homeodomain transcription factor 2 & -2.06 & 0.25 & 0.12 \\
\hline AF002283 & Actinin alpha 2 associated LIM protein & 2.01 & 0.12 & 0.25 \\
\hline AB013345 & Potassium channel, subfamily K, mem. 3 & 2.04 & 0.13 & 0.27 \\
\hline M30774 & Thymidylate synthase pseudogene & 2.08 & 0.21 & 0.45 \\
\hline C76643 & DNA segment, Chr 15, ERATO Doi 30 & 2.12 & 0.14 & 0.31 \\
\hline AV229143 & Interferon activated gene 202A & 2.13 & 0.21 & 0.45 \\
\hline U10341 & A kinase (PRKA) anchor protein 4 & 2.16 & 0.12 & 0.26 \\
\hline V00714 & Hemoglobin alpha, adult chain 1 & 2.2 & 6.59 & 14.71 \\
\hline AB019558 & Parkin & 2.21 & 0.18 & 0.41 \\
\hline AV330895 & Ubiquintin c-terminal hydrolase related polypeptide & 3.2 & 0.12 & 0.4 \\
\hline J00413 & Hemoglobin, beta adult major chain & 3.38 & 7.51 & 25.72 \\
\hline AJ002522 & Myosin, heavy polypeptide 1 , skeletal muscle, adult & 4.44 & 0.29 & 1.3 \\
\hline \multicolumn{5}{|l|}{ ESTS } \\
\hline AW125849 & ESTs & -2.37 & 0.42 & 0.18 \\
\hline AI196645 & ESTs & -2.15 & 1.46 & 0.69 \\
\hline AW125480 & ESTs & 2.02 & 0.83 & 1.7 \\
\hline AW120925 & ESTs & 2.18 & 0.16 & 0.35 \\
\hline
\end{tabular}

Affymetrix microarrays encompassing $\sim 1.25 \times 10^{4}$ mouse genes were hybridized with mRNA from KAT-4 carcinomas treated with Fc:T $\beta$ RII $(n=3)$ or with $\operatorname{IgG}_{2 \mathrm{~A}}(n=3)$. A set of 41 genes that fulfilled the following two criteria are listed: significant up- or downregulation between the two groups $(P<0.05$; ANOVA); and upregulation by $\geq 100 \%$ or downregulation by $\geq 50 \%$.

tumors treated with $\operatorname{IgG}_{2 \mathrm{~A}}(n=5 ; P<0.0026)$ (Figure 1b). The microarray analyses showed a particularly strong downregulation of mRNAs encoding MHC class II antigens (Table 1). Expression of MHC class II antigens in KAT-4 carcinoma was largely restricted to a subset of F4/80-positive macrophages
(Figure 1d). CD31-positive vessels expressing MHC class II antigens could not be positively identified. Double immunofluorescence and confocal analyses revealed that $54 \pm 15 \%$ of $\mathrm{F} 4 / 80$-positive macrophages were also positive for MHC class II antigens in control tumors (Figure 1c) but only $16 \pm 3 \%$ in 
516
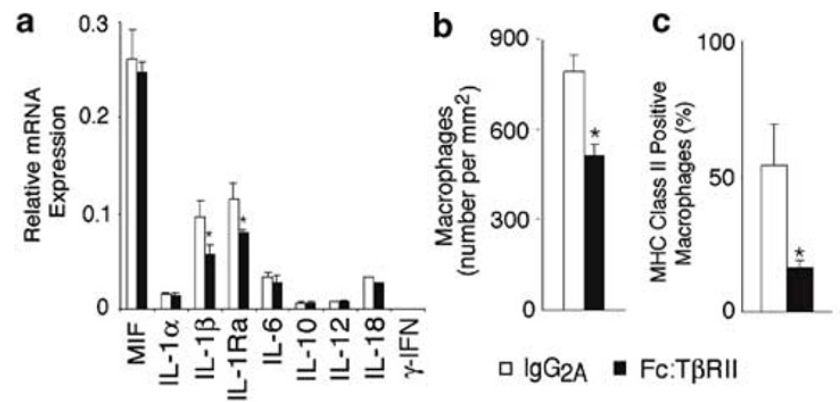

d

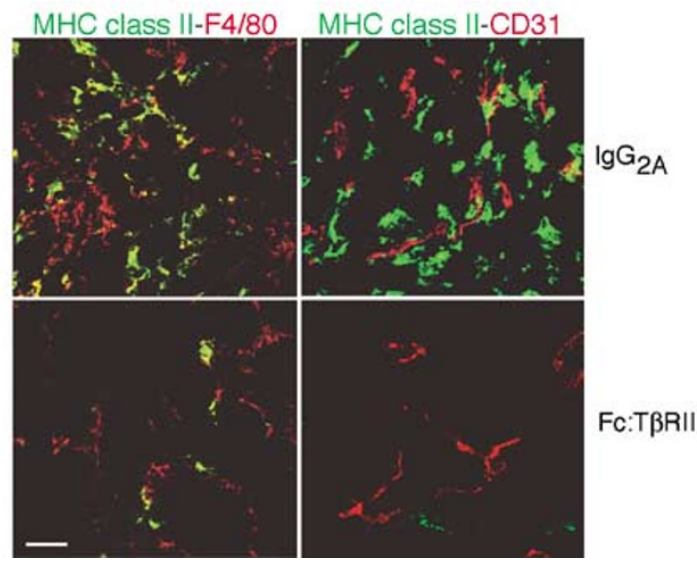

Figure 1 Fc:T $\beta$ RII modulated macrophages in KAT-4 carcinomas. Expression of a set of cytokine mRNAs in KAT-4 carcinomas treated with Fc:T $\beta$ RII $(n=3)$ or $\operatorname{IgG}_{2 \mathrm{~A}}(n=3)$. (a) Carcinoma RNA was extracted 10 days after a single injection of $F_{C}: T \beta R I I ~(10 \mathrm{mg} /$ $\mathrm{kg})$ or $\mathrm{IgG}_{2 \mathrm{~A}}(10 \mathrm{mg} / \mathrm{kg})$ and samples were subjected to RPA. (b) Density of F4/80-positive tumor macrophages in KAT-4 carcinomas treated with Fc:T $\beta$ RII (filled bars, $n=5$ ) or $\operatorname{IgG}_{2 \mathrm{~A}}$ (open bars, $n=5$ ). In (c) and (d), double immunofluorescence stainings and confocal analyses were used to evaluate and quantify the expression of MHC class II antigens (green) by F4/80-positive intratumoral macrophages or CD31-positive endothelial cells (red). In (d) yellow color identifies a subset of F4/80-positive macrophages expressing MHC class II antigens (left panel) or expression of MHC class II antigens by CD31-positive endothelial cells (right panel). Representative pictures from four to five tumors per experimental group are shown. Bar, $40 \mu \mathrm{m} .{ }^{*}$ indicates $P<0.05$ from $\mathrm{IgG}_{2 \mathrm{~A}}$ controls.

tumors treated with Fc:T $\beta$ RII. Granulocytes comprised around $1 \%$ of the cell mass in KAT-4 carcinomas and their number was not changed after inhibition of TGF- $\beta 1$ and $-\beta 3$ (data not shown).

\section{Inhibition of TGF- $\beta 1$ and - $\beta 3$ Modifies Vascular Morphology}

The effects of Fc:T $\beta$ RII on IFP in KAT-4 carcinomas may be due to changes in vascular function. This is based on the finding that inhibitors of the VEGF system lower tumor IFP and 'normalize' vascular function in carcinoma. ${ }^{14,26}$ We therefore investigated potential effects of vessel maturation after treatment of KAT-4 carcinoma with Fc:T $\beta$ RII. Expression of NG2 protein was downregulated (Figure 2a), whereas $\alpha$ SMA expression was either unaffected or slightly upregulated (Figure 2a). The percentage of CD31-positive vessels that were also positive for
aSMA was significantly increased in tumors treated with Fc:T $\beta$ RII (Figure 2b, c). In addition, more aSMA-expressing extravascular cells were present in tumors treated with $\mathrm{Fc}_{\mathrm{c}} \mathrm{T} \beta \mathrm{RII}$ than with $\operatorname{IgG}_{2 \mathrm{~A}}$ (arrows in Figure 2b). To investigate blood perfusion in KAT-4 carcinomas, tumor-bearing mice were injected with high molecular mass FITC-labeled dextran prior to killing. There was no significant difference between the number or distribution of perfused vessels (Figure 2f) in tumors treated with Fc:T $\beta$ RII $\left(65 \pm 24\right.$ vessels per $\left.\mathrm{mm}^{2}, n=5\right)$ and $\operatorname{IgG}_{2 \mathrm{~A}}$ controls (65 \pm 12 vessels per $\left.\mathrm{mm}^{2}, n=4\right)$. Vessel integrity was investigated by semiquantitative analyses of the leakage of EBD. ${ }^{27}$ In the circulation, EBD is irreversibly bound to albumin. EBD present in tissues, therefore, reflects albumin leakage from capillaries. $^{28}$ Treatment of mice bearing KAT-4 carcinomas with Fc:T $\beta$ RII reduced EBD leakage in the carcinomas compared to $\operatorname{IgG}_{2 \mathrm{~A}}$ treatment (Figure 2f). The significance of this difference was assessed by a grading procedure (Figure $2 \mathrm{~d}$ ) or by densitometric analysis (Figure 2e).

Together these data suggest that Fc:T $\beta$ RII normalized blood vessels with regard to pericyte activation, $\alpha$-SMA coverage and extravasation of albumin.

\section{Inhibition of IL-1 Reduces Tumor IFP}

The gene expression data, as well as immunohistochemical analyses, suggested that interference with TGF- $\beta 1$ and/or $-\beta 3$ modulated macrophages in KAT4 carcinomas. Since IL- $1 \beta$ was reduced after treatment with Fc:T $\beta$ RII and since it is secreted by activated macrophages, its potential role in maintaining a high IFP in KAT-4 carcinoma was investigated. Treatment of mice carrying KAT-4 carcinomas with rh-IL-1 Ra $(n=9)$ significantly reduced IFP to a similar degree as treatment with Fc:T $\beta$ RII $(n=15 ; P<0.05)$ (Figure 3 and data from Lammerts et $\left.a 1^{19}\right)$. Combined treatment of animals with Fc:T $\beta$ RII and rh-IL-1 Ra $(n=7)$ had no additive effect on IFP compared to any of the inhibitors alone (Figure 3).

The number of infiltrating macrophages was reduced by $43 \%$ to $453 \pm 54$ cells per $\mathrm{mm}^{2}$ $(9.5 \pm 1.3 \%$ of total cellular density) after treatment with rh-IL-1 Ra $(n=4)$ (cf Figure 1b). Furthermore, the fraction of MHC class II antigens expressing F4/ 80 -positive macrophages was reduced by $28 \%$ in rh-IL-1 Ra-treated carcinomas compared to controls.

\section{Inhibition of IL-1 had No Effect on Vascular Morphology}

Whereas expression of NG2 protein was downregulated in KAT-4 carcinomas treated with Fc:T $\beta$ RII, treatment with rh-IL-1 Ra did not decrease this expression (data not shown). Qualitative immunofluorescence analyses revealed no significant change in perivascular $\alpha \mathrm{SMA}$-expressing cells in 
KAT-4 carcinomas treated with rh-IL-1 Ra compared to controls (data not shown). Furthermore, no significant change in the percentage of CD31 positive vessels that were also positive for $\alpha \mathrm{SMA}$ was observed after treatment with rh-IL-1 Ra (Figure 4a). However, there was a trend for a decreased extravasation of albumin after treatment with rh-IL-1 $\mathrm{Ra}$ although this effect did not reach significance (Figures $4 \mathrm{~b}$ and $\mathrm{c}$ ).

\section{Inhibition of TGF- $\beta 1$ and $-\beta 3$ or IL-1 did not Influence Angiogenesis}

The microarray analyses of KAT-4 tumors showed no changes in expression of genes associated with vascular function. Furthermore, expressions of several mouse mRNAs encoding various markers of angiogenesis were similar in KAT-4 carcinomas from

a

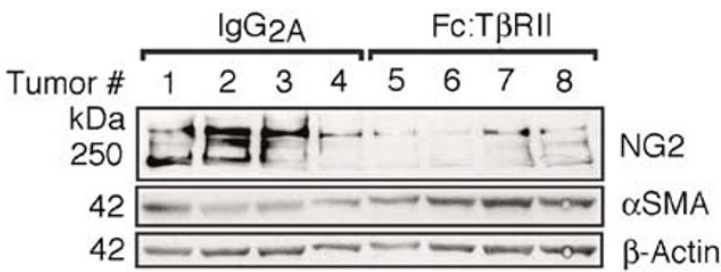

b

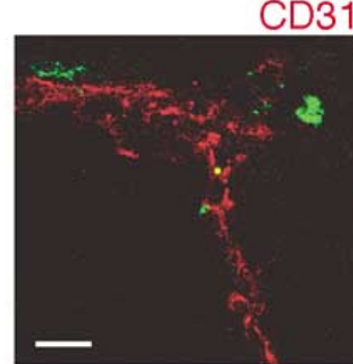

$\lg \mathrm{G}_{2 \mathrm{~A}}$

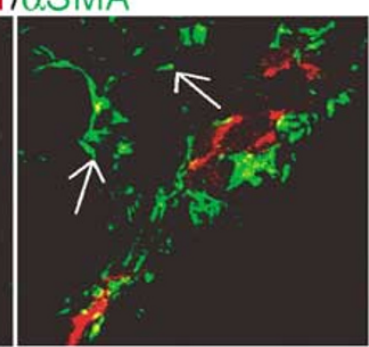

Fc:T $\beta R I I$
C
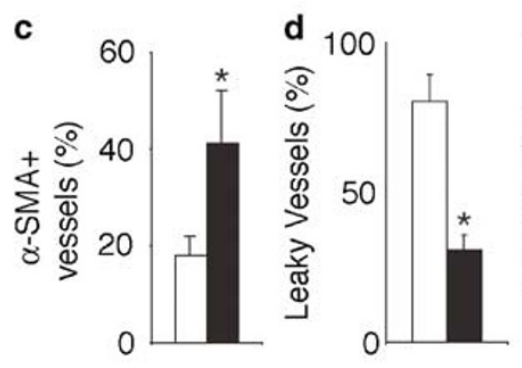

e

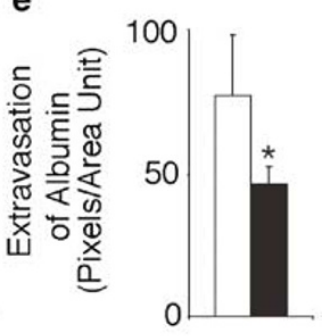

$\mathbf{f}$

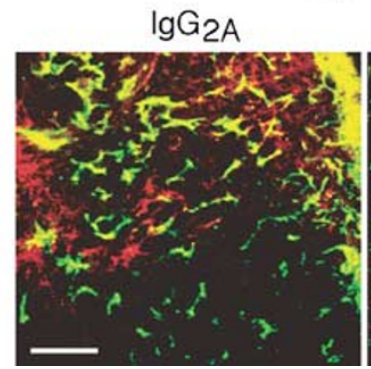

animals treated either with $\operatorname{IgG}_{2 \mathrm{~A}}, \mathrm{Fc}: \mathrm{T} \beta \mathrm{RII}$ or rh-IL1 Ra (Figure 5a). Notably, the expression of human VEGF mRNA was similar in the different groups of carcinomas (Figure 5b). Production of VEGF by cultured KAT- 4 cells was $\sim 0.2 \mathrm{ng} / \mathrm{h} / 10^{6}$ cells and this production was not affected by the addition of Fc:T $\beta$ RII or rh-IL-1 Ra to the culture media (data not shown). Furthermore, levels of VEGF relative to total protein in extracts from KAT-4 carcinomas treated with Fc:T $\beta$ RII or rh-IL-1 Ra were not different from the respective controls (data not shown).

Microvessel density and distribution within the viable zone was similar in carcinomas treated with FC:T $\beta$ RII $(n=4)$, rh-IL-1 Ra $(n=6)$ or $\operatorname{IgG}_{2 \mathrm{~A}}(n=4)$ when assessed by morphometry of CD31 positive structures (Figure 5c). Similar results were obtained when vessels were visualized by staining for the 'panendothelial cell antigen' (data not shown). Laminin was expressed in vascular basement membranes and this expression was not qualitatively affected by either of the two inhibitors (data not shown). Expression of VEGFR-3 and lymphatic vessel endothelial HA-receptor-1 were not detectable in the viable zone of tumors treated with Fc:T $\beta$ RII, rh-IL-1 Ra or $\operatorname{IgG}_{2 \mathrm{~A}}$ (data not shown).

\section{Inhibition of TGF- $\beta 1$ and - $\beta 3$ Augments Efficacy of Doxorubicin}

The potential of treatment with Fc:T $\beta$ RII to augment chemotherapy was investigated. Animals with KAT4 carcinomas were pretreated with $1 \mathrm{mg} / \mathrm{kg}$ of Fc:T $\beta$ RII $(n=4)$, or $\operatorname{IgG}_{2 \mathrm{~A}}(n=4)$. Starting 10 days after the administration of Fc:T $\beta$ RII animals were treated for 2 weeks with doxorubicin in a dose

Figure 2 Fc:T $\beta$ RII matured blood vessels and reduced albumin extravasation in KAT-4 carcinomas. (a) Immunoblot analysis of KAT-4 carcinoma tissue for mural cell markers expression. Tumor tissue samples were obtained from mice that had received a single injection of $\mathrm{Fc}_{\mathrm{C}} \mathrm{T} \beta \mathrm{RII}(10 \mathrm{mg} / \mathrm{kg})(n=4)$ or $\operatorname{IgG}_{2 \mathrm{~A}}(n=4) 10$ days prior to harvest of carcinoma. $\beta$-Actin was used as a control for loading. Double immunofluorescence and confocal microscopy were used (b) to evaluate $\alpha \mathrm{SMA}$ expression (green) in cells associated with CD31-positive tumor vessels (red). White arrows indicate on $\alpha$ SMA-expressing cells localized in tumor interstitium. Bar, $20 \mu \mathrm{m}$. (c) Quantification of vessels containing $\alpha$ SMApositive cells in KAT-4 carcinoma treated with Fc:T $\beta$ RII. Tumor sections were stained by double immunofluorescence for CD31 and $\alpha$ SMA. The percentage of vessels covered by $\alpha$ SMA positive cells out of total vascular density was quantified in low power fields (tumors from three animals per group, investigated area per tumor $3-6 \mathrm{~mm}^{2}$ ). Densitometric and semiquantitative analysis of EBD vascular leakage $(\mathbf{d , e})$ in KAT-4 carcinomas treated with Fc:T $\beta$ RII $(n=5)$ and $\operatorname{IgG}_{2 \mathrm{~A}}(n=5)$. Leakage of tumor vessels for albumin was assessed using an EBD permeability assay. Perfused vessels were visualized by FITC-Dextran (2000 kDa). Tumor tissue samples were analyzed by microscopy as described in Materials and methods. One area unit corresponds to $69 \mu \mathrm{m}^{2}$. In (d) data are presented as percentage of vessels with high leakage for EBD. In (f) leakage of tumor vessels for EBD is shown in red. Perfused area of tumor tissue was assessed by analyses of FITC-Dextran distribution (green). Bar, $200 \mu \mathrm{m}$. * indicates $P<0.05$ from $\operatorname{IgG}_{2 \mathrm{~A}}$ control. 


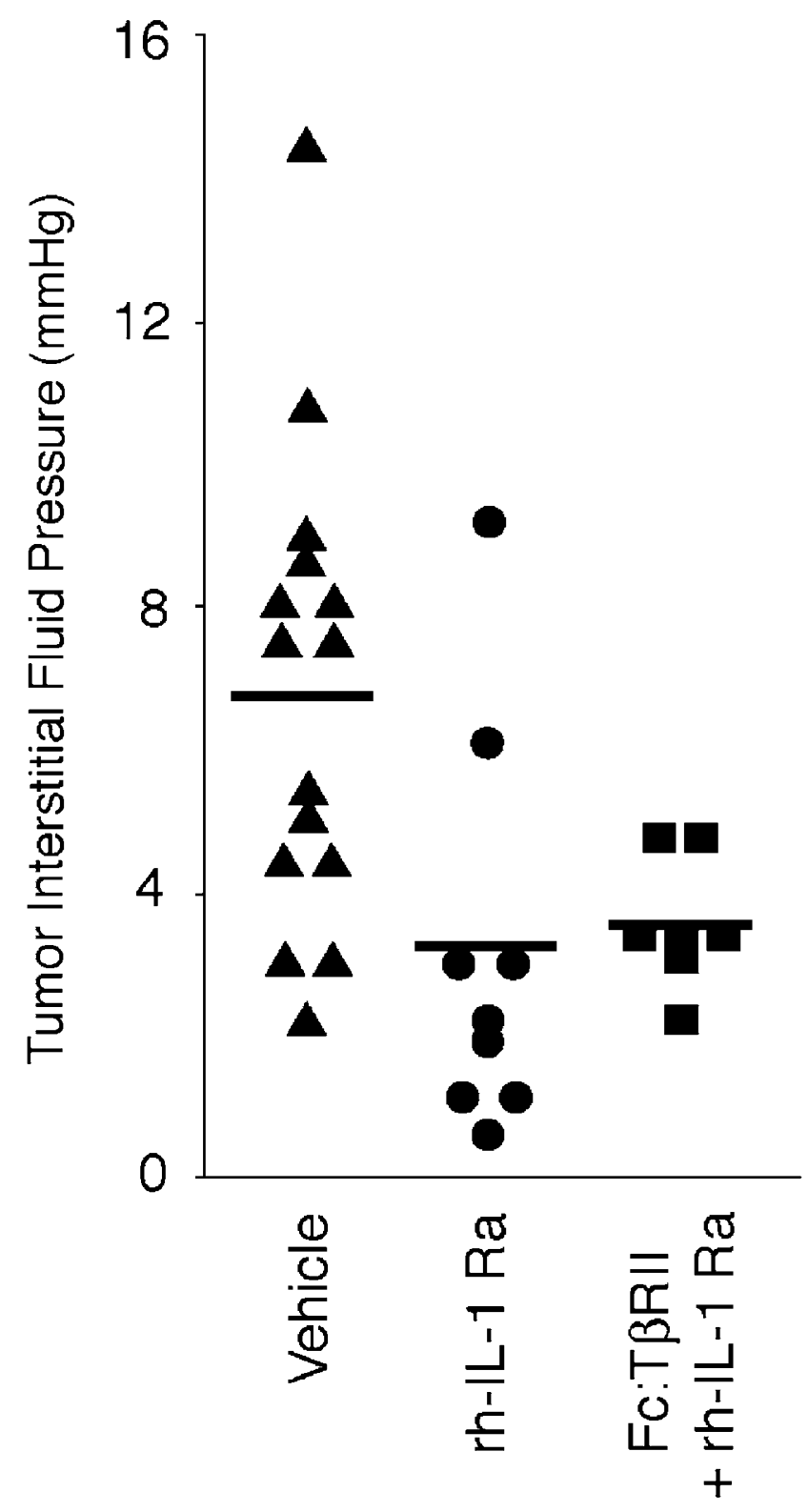

Figure 3 Inhibition of IL-1 lowered tumor IFP in KAT-4 carcinomas. Administration of rh-IL-1 Ra twice daily for 10 days with $7.5 \mathrm{mg} /$ injection to KAT-4 carcinoma-bearing mice lowered tumor IFP by around $50 \%$, that is, to the similar degree as Fc:T $\beta$ RII alone. ${ }^{19}$ There was no additive effect on tumor IFP observed after combined treatment with Fc:T $\beta$ RII (a single injection at a dose of $10 \mathrm{mg} / \mathrm{kg}$ ) and rh-IL-1 Ra.

pretitrated to have minimal effects on tumor growth. Control animals received a single injection of Fc:T $\beta$ RII alone at a dose of $1 \mathrm{mg} / \mathrm{kg}(n=4)$. The dose of $1 \mathrm{mg} / \mathrm{kg}$ of $\mathrm{Fc}_{\mathrm{c}} \mathrm{T} \beta \mathrm{RII}$ was chosen since it was the lowest dose of Fc:T $\beta$ RII which reduced IFP in KAT-4 carcinoma. ${ }^{19}$

The antitumor effect of doxorubicin was significantly greater after pretreatment with Fc:T $\beta$ RII compared to $\operatorname{IgG}_{2 \mathrm{~A}}$ (Figure 6a). In contrast, the growth inhibitory effect of doxorubicin on cultured KAT-4 cells was not influenced by the presence of either TGF- $\beta 1$ or Fc:T $\beta$ RII (Figure 6b).
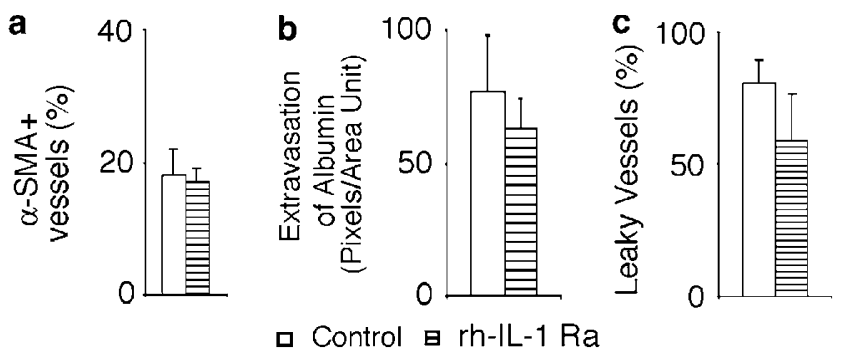

Figure 4 Effects of rh-IL-1-Ra on blood vessel maturation and albumin extravasation. In (a) quantification of vessels containing aSMA-positive cells in KAT-4 carcinoma treated with rh-IL-1 Ra twice daily with $7.5 \mathrm{mg} /$ injection for 10 days $(n=4)$. Tumor sections were stained by double immunofluorescence for CD31 and $\alpha$ SMA. Leakage of tumor vessels for albumin was assessed using an EBD permeability assay. In (b) and (c) densitometric and semiquantitative analysis of EBD vascular leakage in KAT-4 carcinomas treated with rh-IL-1 Ra $(n=4)$ and $\operatorname{IgG}_{2 \mathrm{~A}}(n=5)$. Perfused vessels were visualized by FITC-Dextran $(2000 \mathrm{kDa})$. Tumor tissue samples were analyzed by microscopy as described in Materials and methods. One area unit corresponds to $69 \mu \mathrm{m}^{2}$. In (c) data are presented as percentage of vessels with high leakage for EBD.

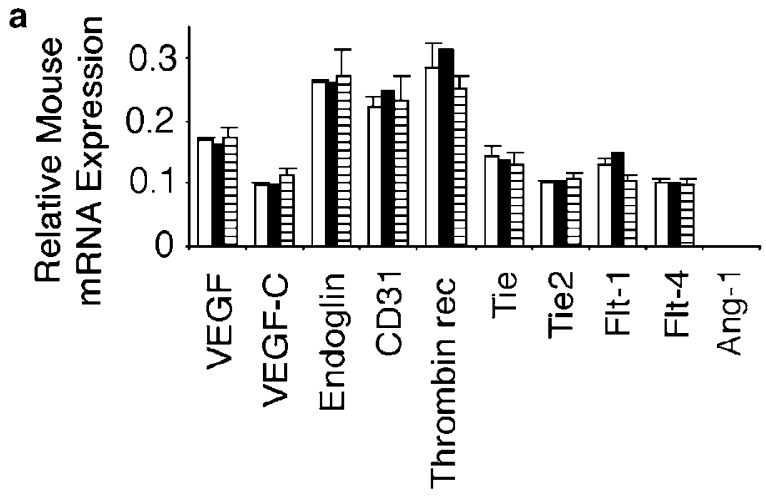

b

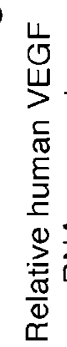

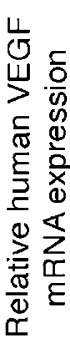

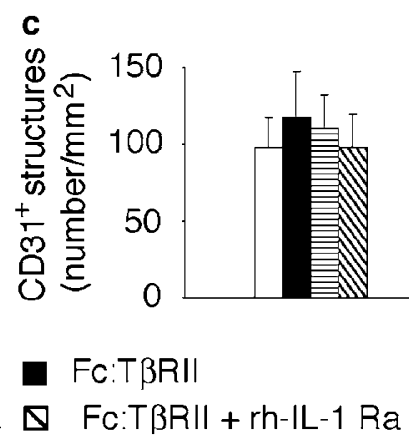

Figure 5 Fc:T $\beta$ RII and rh-IL-1 Ra had no effects on angiogenesis. (a) Expression of a set of mouse genes involved in angiogenesis was investigated in KAT-4 carcinomas treated with Fc:T $\beta$ RII $(n=2), \operatorname{IgG}_{2 \mathrm{~A}}(n=3)$ or rh-IL-1 Ra $(n=3)$ (b) Carcinoma RNA was extracted and subjected to RPA 10 days after a single injection of Fc:T $\beta$ RII $(10 \mathrm{mg} / \mathrm{kg})$ or $\mathrm{IgG}_{2 \mathrm{~A}}(10 \mathrm{mg} / \mathrm{kg})$ or after treatment with rhIL-1 Ra for 10 days (7.5 mg/injection, twice daily). RPA analyses of levels of human VEGF (KAT-4 cells) mRNA. (c) Microvessels were identified by immunohistochemistry with anti-CD31/PECAM-1 Mab in KAT-4 carcinomas treated with Fc:T $\beta$ RII $(n=4)$, rh-IL-1 Ra

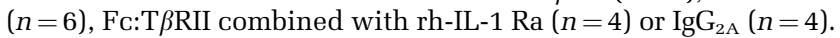
The density of CD31-positive structures was counted and expressed as number per $\mathrm{mm}^{2}$ of tumor viable zone (5-22 vision fields, $\times 200)$. 

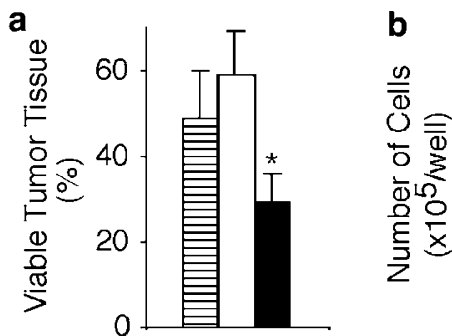

日 FC:T $\beta R \|$

$\square \lg G_{2 A}+$ doxorubicin

- FC:T $\beta R \|$ + doxorubicin

Figure 6 Pretreatment with Fc:T $\beta$ RII increased efficacy of doxorubicin in KAT-4 carcinomas in vivo. In (a) KAT-4 tumorbearing mice were pretreated with a single injection of Fc:T $\beta$ RII $(1 \mathrm{mg} / \mathrm{kg})$ or $\mathrm{IgG}_{2 \mathrm{~A}}$. After 10 days, animals received doxorubicin at a dose of $3 \mathrm{mg} / \mathrm{kg}$ every second day during a two week period. Control animals received a single injection of $F_{C}: T \beta R I I$ at a dose of $1 \mathrm{mg} / \mathrm{kg}$. Pretreatment with Fc:T $\beta$ RII increased treatment efficacy of doxorubicin as evident by a reduction of KAT-4 viable tumor tissue. In (b) influence of addition of Fc:T $\beta$ RII $(100 \mathrm{nM})$ or TGF- $\beta 1$ $(10 \mathrm{ng} / \mathrm{ml})$ to cultured KAT- 4 cell on the growth inhibitory effects of doxorubicin. * indicates $P<0.05$ from $\operatorname{IgG}_{2 \mathrm{~A}}$ controls.

\section{Discussion}

The present data suggest that carcinoma-associated macrophages are involved in the regulation of IFP in experimental carcinoma. First, analyses of global gene expression patterns in KAT-4 carcinoma revealed that genes expressed by macrophages constituted a major group of genes that were downregulated after interference with TGF- $\beta 1$ and $-\beta 3$. Genes encoding MHC class II antigens, mannose receptors, IL-1 $\beta$, S100 calcium-binding protein A9 (MRP-14) and the chemokine MCP-2 were downregulated. Since MHC class II antigens expression could only be positively identified in F4/80-positive macrophages, the downregulation of MHC class II antigens strongly suggests that macrophages are targeted by Fc:T $\beta$ RII. Second, the number of intratumoral macrophages decreased after administration of Fc:T $\beta$ RII, an effect coinciding with the lowering of tumor IFP. The reduction in macrophage numbers after treatment with the TGF- $\beta$ inhibitor is in line with the well-established function of TGF- $\beta 1$ as a chemoattractant for monocytes. ${ }^{29,30}$ Third, the specific IL-1 inhibitor, rh-IL-1 Ra reduced IFP in KAT-4 carcinoma. Macrophages are major producers of secreted IL- $1 \beta$ in reactive tissues ${ }^{31}$ and cultured KAT- 4 cells secreted neither IL- $1 \alpha$ nor $-1 \beta$ (data not shown). The expression of mouse IL- $1 \alpha$ mRNA was low in KAT-4 carcinomas, suggesting that the effects of rh-IL-1 Ra on tumor IFP were due to inhibition of IL-1 $\beta$. TGF- $\beta$ induces IL-1 $\beta$ mRNA expression by cultured human monocytes, ${ }^{29}$ a finding in line with the present result that inhibition of TGF- $\beta 1$ and $-\beta 3$ reduced IL-1 $\beta$ mRNA in KAT-4 carcinomas. In addition, treatment with the anti-inflammatory drug dexamethasone reduced macrophage density, ex- pression of MHC class II antigens by macrophages and lowered IFP in KAT-4 carcinoma (data not shown). It is noteworthy that inhibitors of several growth factors or cytokines that are produced by activated macrophages, such as PDGF, ${ }^{9}$ TGF- $\beta 1$ and $\beta 3,{ }^{19} \mathrm{IL}-1$ (present study) and VEGF ${ }^{10}$ lower IFP in experimental carcinoma.

Expression of MHC class II antigens and mannose receptors by macrophages serve as markers of activation of these cells. ${ }^{32} \mathrm{Fc}$ :T $\beta$ RII markedly downregulated class II expression by macrophages in KAT-4 carcinomas demonstrating that this inhibitor deactivated or, alternatively inhibited the activation of intratumoral macrophages. Both rh-IL-1 Ra and Fc:T $\beta$ RII reduced the number of macrophages by $\sim 30-40 \%$ in KAT-4 carcinoma tissue, but no linear correlation between macrophage numbers and KAT4 carcinoma IFP could be established (data not shown). Based on these notions, it therefore seems plausible that macrophage activation rather than number is important for their putative effects on tumor IFP.

Microvessel density in KAT-4 carcinomas was not affected by treatment with either Fc:T $\beta$ RII or rh-IL-1 Ra. These findings show that the lowering of tumor IFP was not due to antiangiogenic effects of these inhibitors. However, treatment with Fc:T $\beta$ RII significantly decreased extravasation of albumin in the carcinomas. A reduced protein leakage presumably reflects a normalization or maturation of the carcinoma vasculature. The decrease in NG2 expression, a marker of activated pericytes, ${ }^{24,33,34}$ thus likely reflected a change in pericyte phenotype towards one more resembling that prevalent in normal and mature microvessels. The higher percentage of CD31 positive vessels containing $\alpha \mathrm{SMA}$-positive cells also favors the notion of a maturation of blood vessels in KAT-4 carcinomas from mice treated with Fc:T $\beta$ RII. These findings speak in favor of a mechanism for IFP lowering by Fc:T $\beta$ RII involving maturation of tumor blood vessels in KAT-4 carcinoma. Inhibition of IL-1 reduced IFP to a similar degree as Fc:T $\beta$ RII but had less pronounced or no effects on the parameters for blood vessel maturation that were investigated. Furthermore, inhibition of IL-1 reduced albumin extravasation albeit this effect was not statistically significant. It is thus possible that Fc:T $\beta$ RII and rh-IL-1 Ra lower tumor IFP by different mechanisms. Alternatively, the two inhibitors lowered IFP in KAT-4 carcinoma by a common mechanism involving subtle changes in blood vessel maturation. The finding that rh-IL-1 Ra reduced IFP in a nonadditive manner to Fc:T $\beta$ RII is compatible with a common mechanism for lowering of carcinoma IFP by Fc:T $\beta$ RII and rh-IL-1 Ra.

VEGF potently stimulates protein leakage from blood vessels ${ }^{35}$ and activates nonendothelial vascular cells, for example, NG2 expression by pericytes in in vivo models of VEGF driven vasculogenesis. ${ }^{36}$ The proangiogenic activity of IL- $1 \alpha$ has been ascribed to a stimulation of VEGF production by 
inflammatory cells. ${ }^{37}$ Furthermore, treatment with inhibitors of the VEGF system reduces IFP, microvessel density and plasma protein leakage in experimental, ${ }^{26}$ as well as human rectal carcinoma. ${ }^{14}$ An attractive model is therefore that the effects of FC:T $\beta$ RII and rh-IL-1 Ra at least in part were due to a reduction of VEGF activity in KAT-4 carcinoma. The present findings do, however, not favor such a model. First and most importantly, neither Fc:T $\beta$ RII nor rh-IL-1 Ra reduced microvessel density in KAT-4 carcinoma. This would be expected if inhibition of the VEGF system constituted a common mechanism for the IFP lowering by the two inhibitors. Second, levels of human and mouse VEGF mRNAs and protein were not changed in KAT-4 carcinomas treated with any of the two inhibitors. Third, VEGF production by cultured KAT-4 cells was not changed by the presence of Fc:T $\beta$ RII or rh-IL-1 Ra (data not shown). Based on these findings it seems less likely that modulations of VEGF levels constituted a common mechanism for IFP lowering by Fc:T $\beta$ RII or rh-IL-1 Ra.

Long-term presence of Fc:T $\beta$ RII suppresses metastasis formation in experimental tumor models. $^{17,18}$ The present data showing that Fc:T $\beta$ RII increases efficacy of chemotherapy should add to the clinical potential for adjuvant treatment of advanced malignancies using specific Fc:T $\beta$ RII.

In conclusion, we present evidence suggesting that macrophages play a role in the generation of the pathologically elevated tumor IFP in a model for experimental carcinoma. Furthermore, our data propose that TGF- $\beta 1$ and/or $-\beta 3$ modulate macrophages in carcinoma.

\section{Acknowledgements}

This study was supported by grants from the Swedish Cancer Foundation, Gustaf V:s 80-årsfond (to KR) and Swedish Research Council (to NEH). Ms Ann-Marie Gustafson and Ms Annika Hermansson are gratefully acknowledged for technical assistance.

\section{References}

1 Tannock IF, Lee CM, Tunggal JK, et al. Limited penetration of anticancer drugs through tumor tissue: a potential cause of resistance of solid tumors to chemotherapy. Clin Cancer Res 2002;8:878-884.

2 Jain RK. Transport of molecules in the tumor interstitium: a review. Cancer Res 1987;47:3039-3051.

3 Jain RK. Physiological barriers to delivery of monoclonal antibodies and other macromolecules in tumors. Cancer Res 1990;50:814s-819s.

4 Wiig $\mathrm{H}$, Tveit E, Hultborn R, et al. Interstitial fluid pressure in DMBA-induced rat mammary tumours. Scand J Clin Lab Invest 1982;42:159-164.

5 Rubin K, Sjöquist M, Gustafsson AM, et al. Lowering of tumoral interstitial fluid pressure by prostaglandin $\mathrm{E}_{1}$ is paralleled by an increased uptake of ${ }^{51} \mathrm{Cr}$-EDTA. Int J Cancer 2000;86:636-643.

6 Salnikov AV, Iversen VV, Koisti M, et al. Lowering of tumor interstitial fluid pressure specifically augments efficacy of chemotherapy. FASEB J 2003;17:1756-1758.

7 Emerich DF, Dean RL, Snodgrass P, et al. Bradykinin modulation of tumor vasculature: II. Activation of nitric oxide and phospholipase A2/prostaglandin signaling pathways synergistically modifies vascular physiology and morphology to enhance delivery of chemotherapeutic agents to tumors. J Pharmacol Exp Ther 2001;296:632-641.

8 Aukland K, Reed RK. Interstitial-lymphatic mechanisms in the control of extracellular fluid volume. Physiol Rev 1993;73:1-78.

9 Pietras K, Östman A, Sjöquist M, et al. Inhibition of platelet-derived growth factor receptors reduces interstitial hypertension and increases transcapillary transport in tumors. Cancer Res 2001;61:2929-2934.

10 Lee CG, Heijn M, di Tomaso E, et al. Anti-vascular endothelial growth factor treatment augments tumor radiation response under normoxic or hypoxic conditions. Cancer Res 2000;60:5565-5570.

11 Kristjansen PE, Boucher Y, Jain RK. Dexamethasone reduces the interstitial fluid pressure in a human colon adenocarcinoma xenograft. Cancer Res 1993;53: 4764-4766.

12 Pietras K, Rubin K, Sjöblom T, et al. Inhibition of PDGF receptor signaling in tumor stroma enhances antitumor effect of chemotherapy. Cancer Res 2002;62: 5476-5484.

13 Pietras K, Stumm M, Hubert M, et al. STI571 enhances the therapeutic index of epothilone B by a tumorselective increase of drug uptake. Clin Cancer Res 2003;9:3779-3787.

14 Willett CG, Boucher Y, Di Tomaso E, et al. Direct evidence that the VEGF-specific antibody bevacizumab has antivascular effects in human rectal cancer. Nat Med 2004;10:145-147.

15 Heldin CH, Rubin K, Pietras K, et al. High interstitial fluid pressure-an obstacle in cancer therapy. Nat Rev Cancer 2004;4:806-813.

16 Roberts AB, Wakefield LM. The two faces of transforming growth factor $\beta$ in carcinogenesis. Proc Natl Acad Sci USA 2003;100:8621-8623.

17 Muraoka RS, Dumont N, Ritter CA, et al. Blockade of TGF- $\beta$ inhibits mammary tumor cell viability, migration, and metastases. J Clin Invest 2002;109: 1551-1559.

18 Yang YA, Dukhanina O, Tang B, et al. Lifetime exposure to a soluble TGF- $\beta$ antagonist protects mice against metastasis without adverse side effects. J Clin Invest 2002;109:1607-1615.

19 Lammerts E, Roswall P, Sundberg C, et al. Interference with TGF- $\beta 1$ and $-\beta 3$ in tumor stroma lowers tumor interstitial fluid pressure independently of growth in experimental carcinoma. Int J Cancer 2002;102: 453-462.

20 Smith JD, Bryant SR, Couper LL, et al. Soluble transforming growth factor- $\beta$ type II receptor inhibits negative remodeling, fibroblast transdifferentiation, and intimal lesion formation but not endothelial growth. Circ Res 1999;84:1212-1222.

21 Ain KB, Taylor KD. Somatostatin analogs affect proliferation of human thyroid carcinoma cell lines in vitro. J Clin Endocrinol Metab 1994;78: 1097-1102. 
22 Dahlman T, Lammerts E, Bergström D, et al. Collagen type I expression in experimental anaplastic thyroid carcinoma: regulation and relevance for tumorigenicity. Int J Cancer 2002;98:186-192.

23 Auffray C, Rougeon F. Purification of mouse immunoglobulin heavy-chain messenger RNAs from total myeloma tumor RNA. Eur J Biochem 1980;107: 303-314.

24 Sundberg C, Ljungström M, Lindmark G, et al. Microvascular pericytes express platelet-derived growth factor- $\beta$ receptors in human healing wounds and colorectal adenocarcinoma. Am J Pathol 1993;143:1377-1388.

25 Reuterdahl C, Sundberg C, Rubin K, et al. Tissue localization of $\beta$ receptors for platelet-derived growth factor and platelet-derived growth factor B chain during wound repair in humans. J Clin Invest 1993; 91:2065-2075.

26 Tong RT, Boucher Y, Kozin SV, et al. Vascular normalization by vascular endothelial growth factor receptor 2 blockade induces a pressure gradient across the vasculature and improves drug penetration in tumors. Cancer Res 2004;64:3731-3736.

27 Gratton JP, Lin MI, Yu J, et al. Selective inhibition of tumor microvascular permeability by cavtratin blocks tumor progression in mice. Cancer Cell 2003;4:31-39.

28 Wolman M, Klatzo I, Chui E, et al. Evaluation of the dye-protein tracers in pathophysiology of the bloodbrain barrier. Acta Neuropathol (Berl) 1981;54:55-61.
29 Wahl SM, Hunt DA, Wakefield LM, et al. Transforming growth factor type $\beta$ induces monocyte chemotaxis and growth factor production. Proc Natl Acad Sci USA 1987;84:5788-5792.

30 Derynck R, Akhurst RJ, Balmain A. TGF- $\beta$ signaling in tumor suppression and cancer progression. Nat Genet 2001;29:117-129.

31 Dinarello CA. Biologic basis for interleukin-1 in disease. Blood 1996;87:2095-2147.

32 Gordon S. Alternative activation of macrophages. Nat Rev Immunol 2003;3:23-35.

33 Schlingemann RO, Rietveld FJ, de Waal RM, et al. Expression of the high molecular weight melanomaassociated antigen by pericytes during angiogenesis in tumors and in healing wounds. Am J Pathol 1990;136:1393-1405.

34 Stallcup WB. The NG2 proteoglycan: past insights and future prospects. J Neurocytol 2002;31:423-435.

35 Veikkola T, Karkkainen M, Claesson-Welsh L, et al. Regulation of angiogenesis via vascular endothelial growth factor receptors. Cancer Res 2000;60:203-212.

36 Witmer AN, van Blijswijk BC, van Noorden CJ, et al. In vivo angiogenic phenotype of endothelial cells and pericytes induced by vascular endothelial growth factor-A. J Histochem Cytochem 2004;52:39-52.

37 Salven P, Hattori K, Heissig B, et al. Interleukin-1 $\alpha$ promotes angiogenesis in vivo via VEGFR-2 pathway by inducing inflammatory cell VEGF synthesis and secretion. FASEB J 2002;16:1471-1473. 